\title{
How To Conceptually Engineer Conceptual Engineering?
}

\author{
Manuel Gustavo Isaac* \\ Swiss National Science Foundation (SNSF) \& \\ Institute for Logic, Language, and Computation (ILLC), \\ University of Amsterdam (UvA)
}

\begin{abstract}
Conceptual engineering means to provide a method to assess and improve our concepts working as cognitive devices. But conceptual engineering still lacks an account of what concepts are (as cognitive devices) and of what engineering is (in the case of cognition). And without such prior understanding of its subject matter, or so it is claimed here, conceptual engineering is bound to remain useless, merely operating as a piecemeal approach, with no overall grip on its target domain. The purpose of this programmatic paper is to overcome this knowledge gap by providing some guidelines for developing the theories of concepts and of cognition that will ground the systematic unified framework needed to effectively implement conceptual engineering as a widely applicable method for the cognitive optimization of our conceptual devices.
\end{abstract}

Keywords. Meta-philosophy, Philosophical methodology, Conceptual engineering, Theory of concepts, Theory of cognition.

... it would be useful if those who believe in concepts and the engineering of them could come up with theoretical frameworks.

H. Cappelen, Fixing Language (2018: 200)

\section{Introduction}

We use concepts all the time to make sense of reality - that of foodstuff types to put the groceries away, of GDP metrics to measure the country's economic progress, of 'force' to explain the falling of bodies in Newtonian mechanics, etc. Here the quality of our cognition seems to crucially depend on the quality of our concepts, so that: The better our concepts are, the better our cognitive activity will be. Just think of the percentage of waste you can recycle thanks to good concepts of selective sorting. Example like this are all around us everyday. And conceptual engineering is the fast-moving research program that precisely means to provide a method to assess and improve our concepts working as such cognitive devices. But conceptual engineering is still a very young field, and it still lacks, to date, an explicit account of its own subject matter - namely, of how concepts (as cognitive devices) and engineering (in the case of conceptual cognition) should be construed within the framework of conceptual engineering. In

${ }^{*}$ Address: University of Amsterdam, Faculty of Humanities, Department of Philosophy, Oude Turfmarkt 141-147, 1012 GC Amsterdam, The Netherlands. Email: isaac.manuelgustavo@gmail.com. 
particular, little attempt has been made so far to capitalize on the extent literature on concepts and cognition in the philosophy of cognitive sciences for the purposes of conceptual engineering. And without such prior understanding of its subject matter, or so it is claimed here, conceptual engineering is bound to remain helpless, merely operating as a piecemeal approach with no overall grip on its target domain (Rem. 1). The purpose of this programmatic paper is to make a progress towards overcoming this knowledge gap, namely, by providing some guidelines for developing the theories of concepts and of cognition that will ground the systematic unified framework needed to effectively implement conceptual engineering as an actionable method. To this end, I will start by presenting in a systematic way the research program of conceptual engineering, with a focus on its foundational issues (Sect. 2). On those grounds, I will next draw from psychological approaches to concepts in order to develop a concept of 'concept' that is the most conducive to the research of conceptual engineering (Sect. 3). Then, with a view to implementing this concept of 'concept' within the methodological framework of conceptual engineering - more precisely, with a view to making sense of the "(re-)engineerability" of concepts so construed - I will build on embodied-embedded approaches to cognition in order to develop a concept of '(cognitive) engineering,' again, that is the most conducive to the research of conceptual engineering (ibid.). And in doing so, I will make the first step towards taking up the bootstrapping challenge that undermines the very project of conceptual engineering in its current state, that is: How to conceptually engineer conceptual engineering? ${ }^{1}$ The successful outcome of this reflexive conceptual engineering project is expected to lay the theoretical foundations for making conceptual engineering a widely applicable method for the cognitive optimization of our conceptual devices (Sect. 4).

Remark 1 (Basic assumption). This paper expressly assumes that conceptual engineering is about engineering concepts, i.e. that it is about engineering and about concepts, on pain on creating a misnomer otherwise, which would obviously make the concept of 'conceptual engineering' a very bad case of conceptual engineering (cf. Cappelen 2018: 53, 104) — call this the self-discrediting predicament, ${ }^{2}$ this basic assumption goes against the unprincipled views according to which conceptual engineering may well be about concepts, subject matters/topics, or terms, more or less indistinctly (e.g. Burgess forthcoming; Prinzing 2017: 4-5; Tanswell 2017: 3 [note 1], 5 [note 5]), and even more so, against the eliminativism of the 'austerity framework' according to which conceptual engineering does not deal with concepts at all (neither, by the way, with something to be engineered), but rather with the way in which we talk about topics (Cappelen 2018: 3 [note 2], 53) — in such cases, I would highly recommend re-labelling the research program 'semantic,' 'lexical,' 'terminological engineering,' depending on the representational devices that are taken to be its subject matter.

\footnotetext{
${ }^{1}$ As laid down by Cappelen (2018: 141 [see also 200]): "Many of those who write about conceptual engineering are unclear on the exact nature of the entities being engineered. [...] The first item on the agenda for such views should be to specify what concepts are, and then present an account of how concepts so construed can be engineered"; such bootstrapping challenge is also acknowledged, with respect to the concept of 'concept' at least, by both Scharp (forthcoming) and Thomasson (forthcoming) — yet, the more and more people seem to come to pay attention to its critical importance for the whole research program of conceptual engineering.

${ }^{2}$ Following Scharp (forthcoming), further reasons why rejecting the "'no concept wing' of the conceptual engineering movement" are that "concept eliminativism is itself a conceptual engineering project" and furthermore, that "defective concepts [viz. such as that of 'concept'] can still be useful" (ibid.) — note that this last reason does not work as a rebuttal against the self-discrediting predicament (as in "'Conceptual engineering' is a bad concept, and yet it may still be useful"), for the issue that is here of concern is not (only) that 'conceptual engineering' would be a bad concept (if conceptual engineering were not to be about concepts), but that it would be a bad concept created by the people who are supposed to enable the creation of better concepts: It is a self-discrediting predicament (hence, the bootstrapping challenge).
} 


\section{The research program}

'Conceptual engineering' is the name of a multi-layered research program. At a meta-theoretical level, it labels a renewed take on philosophy (more specifically, on philosophical methodology) conceived as the study of concepts. And at a theoretical level, it designates a fast-moving research field at the intersection of philosophies of language, mind, cognitive science, and epistemology, depending on the way in which concepts and cognition are more or less explicitly construed for the very purposes of conceptual engineering (cf. Sect. 3). This section focuses on conceptual engineering at a meta-theoretical level with a view to making explicit, in a systematic way, the common ground of its theoretical framework (Sect. 2.1) and practical implementation (Sect. 2.2). Thereby, its purpose is to provide the descriptive information that is needed in order to develop the concept of 'concept' and of '(cognitive) engineering' that would be the most conducive to the research program of conceptual engineering (Sect. 3).

\subsection{Theoretical framework}

2.1.1 The label(s) The label 'conceptual engineering' has recently been popularized by Blackburn (1999: 2) to promote philosophy beyond itself. ${ }^{3}$ Since its inception and up to the most recent developments, the framework has in most cases developed by combining three main features, namely: As an evaluative and normative study of our conceptual apparatuses (e.g. Cappelen 2017: 13; Eklund 2015: 376; Prinzing 2017: 1), endowed with a manufacturing perspective on our conceptual cognition (e.g. Floridi 2011: 293; Scharp forthcoming, 2013: 4, 290; Thomasson forthcoming). ${ }^{4}$ As such, conceptual engineering can be seen as representing a specification of 'conceptual ethics,' which also deals with value and prescription about our concepts (e.g. Plunkett 2015: 843, 2016: 38), but without any explicit productive-creative take on them as cognitive tools, in the label at least (cf. Cappelen and Plunkett forthcoming). ${ }^{5}$ This 'poietic' involvement (Floridi 2011: 283), which is intrinsic and central to the research program of conceptual engineering, underlies the determination of its very target domain.

2.1.2 The target domain Conceptual engineering is originally based on the idea that cognition is a sense-making process that consists in shaping a worldview. ${ }^{6}$ Within this context, the status of our conceptual repertoires and schemes is that of cognitive devices that are designed and used, intentionally or not, by us as cognitive agents (e.g. Eklund 2014: Sect. 2; Prinzing 2017: Sect. 4). And the function of these repertoires and schemes, as such cognitive devices, is to make us shape and edit reality (Cappelen 2018: 53; Floridi 2011: 301), our reality (Floridi

\footnotetext{
${ }^{3}$ Apparently, the label was first coined in Carnapian scholarship (Quine and Carnap 1991: 7, 31), maybe inspired from Carnap's own use of "engineering," with reference to some of the criteria of adequacy for his method of conceptual explication (e.g. ibid.: 66, 911); Brandom (2001: 587) also used 'conceptual engineering,' yet in his case, to denote the kind of naturalized conceptual analysis promoted by Dretske, Fodor, and Millikan (about representational content) - while 'naturalized conceptual analysis' itself is, at the meta-theoretical level of philosophical methodology, the label recently chosen by Machery (2017: Chap. 7) for his 'rebooted' version of conceptual analysis.

${ }^{4}$ To some extent, Cappelen's austerity framework and its "Inscrutable-Lack of Control-Will Keep trying" principle (Cappelen 2018: Sect. 6.3, 7.1-7.5) may seem to be an exception to the last of these three common features of conceptual engineering, as it states that: "The processes involved in conceptual engineering are for the most part inscrutable, and we lack control of them, but nonetheless we will and should keep trying." (ibid.: 73)

${ }^{5} \mathrm{Cf}$. Scharp (forthcoming), however, according to whom the two labels should not be seen "as competitors for describing a single area of philosophy," for conceptual ethics and conceptual engineering merely overlap (without the latter being a species of the former, or vice versa); see also Marques (2017: 45) who criticizes the mislabelling of conceptual ethics on the grounds that it is neither conceptual (or at least, not necessarily), nor ethics.

${ }^{6}$ Exemplarily in Blackburn (1999: 2): "For just as the engineer studies the structure of material things, so the philosopher studies the structure of thought. Understanding the structure involves seeing how parts function and how they interconnect. It means knowing what would happen for better or worse if changes were made. This is what we aim at when we investigate the structures that shape our view of the world. Our concepts or ideas form the mental housing in which we live."
} 
2011: 285; Thomasson forthcoming), or at least our understanding of reality (Floridi 2011: 284), so as to meaningfully interact with it (Eklund 2015: 376; Floridi 2011: 301; Prinzing 2017: 5). In this respect, the domain of conceptual engineering appears to be made of nothing but our conceptual apparatuses, yet targeted, from a cognitive viewpoint, as representational artifactual devices (Burgess and Plunkett 2013a: 1095; Cappelen 2017: 13; Floridi 2011: 291; Plunkett 2015: 846; Simion 2017: 10). This determination of the target domain of conceptual engineering underpins the characterization of its epistemological stance.

2.1.3 The epistemological stance ${ }^{7}$ Against any kind of semantic or reference transparency (cf. Eklund 2015: 377-8), ${ }^{8}$ conceptual engineering generally assumes, as a matter of fact, that our conceptual apparatus crucially determines the quality of our corresponding cognitive activities, and that of our cognition in general (Burgess and Plunkett 2013a: 1091, 1096-7; 30 Machery 2017: 220-4, 239; Plunkett 2016). Such assumption even serves as justificatory ground for putting forward the relevance and importance of running conceptual engineering as research program (Burgess and Plunkett 2013a: 1091-2; Cappelen 2017: 17-8; Scharp forthcoming). And on that ground, against conceptual realism which takes concepts to be human-independent entities (Dutilh Novaes 2016: 78; Prinzing 2017: 6), conceptual engineering further contends that our conceptual apparatus could have been and can be engineered otherwise (Dutilh Novaes 2016: 86; Plunkett 2016: 54). In short, that it can be 're-engineered,' and if needed, that it should be, for the better (Brun 2016: 1233 [note 41], 2017: 2). ${ }^{9}$ Characterizing the epistemological stance of conceptual engineering over its target domain, such "ameliorative interventionism" thereby also sets the agenda for its implementation as research program (Sect. 2.2).

Remark 2 (Main approaches). The ameliorative interventionism that drives the research program of conceptual engineering can be implemented in different ways, which may in turn be reduced to at least two main variants (Scharp forthcoming [see also Thomasson forthcoming]): The metaphysical approach, which means "to evaluate [and improve] our concepts for naturalness or fundamentality" and the pragmatic approach, which means "to evaluate [and improve] our concepts for how well they work" - this paper belongs to the second variant (Sect. 3).

\subsection{Practical implementation}

2.2.1 An evaluative method The main goal of conceptual engineering is commonly identified as that of developing a method for the cognitive optimization of our conceptual apparatuses. What firstly characterizes the implementation of this method is its evaluative dimension (e.g. Burgess and Plunkett 2013a: 1094; Cappelen 2017: 13; Cappelen and Plunkett forthcoming). The basic principle that is widely adopted in this respect is that of a form of functionalism, according to which concepts are some kind of cognitive devices, which, as such, have functions (Eklund 2014: Sect. 2, 2015: 376; Prinzing 2017: 5; Thomasson forthcoming) - that is, play a role in our higher cognitive processes (Machery 2017: 210). Thus, instead of asking 'What is the concept C?' (as classical conceptual analysis does), conceptual engineers focus their inquiry on 'What does the concept $C$ do?' (Prinzing 2017: 24 [cf. Chalmers 2011: 538]). And in order to evaluate whether the concept $C$ does what it does well or not (Eklund 2015: $364,376)$, conceptual engineers usually come to endorse, either a kind of monism/absolutism according to which any concepts should be functionally evaluated with respect to the same,

\footnotetext{
${ }^{6} \mathrm{NB}$. 'epistemological' is used here à la française to denote the position of a discipline towards its subject matter.

${ }^{8}$ Semantic transparency would amount to having some privileged access to the content of our concepts (Machery 2017: 210, 221), whereas referential transparency would mean "looking through" our concepts to the things or classes of things they pick up (Burgess and Plunkett 2013a: 1097).

${ }^{9} \mathrm{~A}$ corollary of that epistemological stance is to be found in Cappelen's Master Argument, according to which every concept should be critically assessed (and improved, if need be), for all of them could have been engineered otherwise, and there is no reason why any of them would have been optimally engineered (Cappelen forthcoming).
} 
unique standard (roughly, that of scientific rationality [e.g. Scharp forthcoming]), ${ }^{10}$ or a kind of pluralism/relativism according to which different concepts should be functionally evaluated with respect to different measures depending on, among other things, the conceptual system they belong to (e.g. Burgess and Plunkett 2013b: 1105, 1109; Thomasson forthcoming) - I defend this latter option below (Rem. 6). In both cases anyway, the evaluation is expected to enable the identification of some potentially improvable features of a concept (e.g. of some conceptual deficiencies [cf. Rem. 3]), and as such it is meant to provide conceptual engineers with information and directions for elaborating normative improving strategies.

Remark 3 (Tractable concepts). Several, more or less liberal options are available with regard to which property qualifies a concept as being tractable by the method of conceptual engineering, namely: Being philosophical or philosophically interesting (Eklund 2015: 377; Löwe and Müller 2011: 143; Scharp forthcoming), possibly due to some intrinsic inconsistency (Scharp 2013: 4, forthcoming); ${ }^{11}$ being deficient at large, whether philosophically or not (Brun 2017: 6; Cappelen 2017: 13, 17-8; Dutilh Novaes 2018: 5; Dutilh Novaes and Reck 2017: 196; Scharp and Shapiro 2017: 257); ${ }^{12}$ belonging to so-called 'open-texture' concepts, be such concepts taken to be deficient or not (Tanswell 2017: 4-5); being designed so as to help solving open questions, "that is, questions that are not answerable in principle empirically or mathematically" (Floridi 2011: 293); ${ }^{13}$ or being any concept whatsoever, whatever its own actual value may be (i.e. independently of any deficiencies to be fixed [Simion 2017: 5-6]), and without any limitation to any purported 'conceptual fixed points' or 'bedrock concepts' (Cappelen 2018: Chap. 18 [cf. Chalmers 2011: Sect. 8; Eklund 2015: Sect. 5]) —I defend this last option below (Sect. 3.1.3).

2.2.2 A normative method The second feature that characterizes the implementation of conceptual engineering as a method for the cognitive optimization of our conceptual apparatuses is its normativity (Plunkett 2015: 830, 843-4). In this respect, the question that conceptual engineers ask is no longer 'What concepts do we have?' (as some plans for classical conceptual analysis do), but rather 'What concepts should we have?' (Dutilh Novaes 2018: 3; Plunkett 2015: 837-8, 843, 2016: 38; Prinzing 2017: 1; Scharp forthcoming) - and perhaps more specifically, whether and how to use a concept (Burgess and Plunkett 2013a: 1096). ${ }^{14}$ Depending on the outcome of the evaluation phase (Sect. 2.2.1), conceptual engineers may then prescribe several different strategies for improving the concept, or cluster of concepts, under consideration, whatever the properties qualifying them as tractable by conceptual engineering may be (Rem. 3). Among these improving strategies, one may first distinguish between the conservative ones, which call for the global preservation of a conceptual state (after evaluation), and the progressive ones, which call for the global or local change of a conceptual state (again, after evaluation).

\footnotetext{
${ }^{10}$ Cf. Carnap's (1950: Chap. 1, 1963) method of explication, which is commonly considered as a precursor of current conceptual engineering driven by a rationalist/scienticist revisionary ideology (Brun 2017: 6; Dutilh Novaes 2018: 5; Dutilh Novaes and Reck 2017: 196) — and which has thus been duly characterized as "conceptual re-engineering for theoretical purposes" (Brun 2016: 1211).

${ }^{11}$ Inconsistency is defined as follows by Scharp and Shapiro $(2017: 257,260)$ : "[A] concept is inconsistent iff it has inconsistent constitutive principles [...], either with each other or with otherwise uncontroversial facts."

${ }^{12}$ One may then make up a taxonomy of conceptual deficiencies by basically opposing theoretical deficiencies (such as non-sense, inconsistency, super-imposition, non-naturalness, etc.) to practical ones, and then specify the practical deficiencies by different types of detrimental effects (such as moral, political, social, etc.) (Simion 2017: $3 \mathrm{ff}$.$) - eventually, one can even further claim with Simion (ibid.: 12) that "likely, most practical deficiencies will$ be sourced in [theoretical] deficiencies," and that "[h]ighly plausibly, also, we will only care about [theoretical] deficiencies to begin with because they tend to have bad moral, social, political, etc. effects."

${ }^{13}$ Cf. Scharp's (forthcoming: Sect. 1-3) 'radical therapeutic program' in which conceptual engineering must be complemented by so-called 'metrological naturalism,' according to whose methodological principle "philosophers should use measurement theory as guide or model in philosophical theorizing" (cf. Sect. 2.2.1).

${ }^{14}$ Indeed, given the principled "functionalism" of conceptual engineering (Sect. 2.2.1), "whether or not to use a concept may ultimately depend (in part) on how it ought to be used if it is used" (Burgess and Plunkett 2013a: 1096).
} 
Then, within the progressive wing, one may distinguish between, on a moderate side, revisionary strategies that advise for the local change of some conceptual state (while preserving something identical), and on a more radical side, transformative strategies that advocate a global change of some conceptual state (without preserving anything identical). Finally, on the radical, transformative wing, one may distinguish between substitutive strategies that introduce wholly new conceptual states in replacement of the former one and eliminative strategies that simply suppress a conceptual state. ${ }^{15}$ All these strategies are available to conceptual engineering. ${ }^{16}$ Furthermore, along the same lines as Carnap's method of explication (Carnap 1950: § 3), several criteria may then serve for assessing the adequacy of the prescribed one - and yet all of them, with some constitutive limitations (Rem. 4). But the fundamental success condition that is shared by any improving strategy anyway is basically to make our conceptual apparatuses cognitively better, for us as cognitive agents, and with respect to their cognitive function at large - e.g. by fixing the identified conceptual deficiencies (Sect. 2.2.1). ${ }^{17}$

Remark 4 (Improving strategies). Two important features are constitutive limitations for the implementation of any improving strategies: First, all of them admit trade-offs (cf. Dutilh Novaes and Reck 2017: 202) - possibly, with no unique and context-independent optimal solution (Machery 2017: 214-7); second, all of them call for open-ended processes - as any re-engineered, or newly engineered concept can always become, in turn, the target of another conceptual (re-)engineering project (Dutilh Novaes 2018: 15; Dutilh Novaes and Reck 2017: 201; Brun 2016: 1237-8, 2017: 10).

\section{The knowledge gap}

The systematic overview of the research program of conceptual engineering has made its main foundational issue salient: What is missing from the research program in its current state is an explicit account of how to construe concepts (as cognitive devices) and engineering (in the case of conceptual cognition) for the very purposes of conceptual engineering (cf. Sect. 2). ${ }^{18}$ In particular, and except Machery (2017: Chap. 7), very little attempt has been made so far to draw on cognitive sciences in order to lay the theoretical foundations of conceptual engineering as research field. And without such theoretical foundations, conceptual engineering will never achieve the systematic unified framework that is needed in order to make it an actionable method for the cognitive optimization of our conceptual devices (Rem. 5). This section provides some programmatic guidelines for developing the theories of concepts and of cognition that may ground conceptual engineering as a systematic unified framework — namely, by laying the groundwork for developing the concepts of 'concept' (Sect. 3.1) and of '(cognitive) engineering'

\footnotetext{
${ }^{15}$ Cf. Dutilh Novaes (2018: 2 [note 3]), who distinguishes transformative and revisionary strategies as operations modifying the meaning and the truth-value, respectively, of the concept(s) under consideration; Prinzing (2017: 9), who contrasts revisions and substitutions as modification of the non-essential and essential features, respectively, of the concept(s) under consideration (revisions being thus construed as "identity-preserving conceptual change" [ibid.: 8]); and Scharp (forthcoming), who characterizes conceptual revisions as change with persistence, whereas substitutions (a.k.a. 'replacements') do not cause any conceptual change, but rather introduce fully new concept(s).

${ }^{16}$ As Plunkett (2015: 842) puts it: "There is no reason, after all, that one can't advocate for a conservative view in conceptual [engineering], rather than a reforming or revolutionary one."

${ }^{17}$ Cf. Simion's (2017: 10) Epistemic Limiting Procedure: "A representational device should be ameliorated iff (1) There is all-things-considered reason to do so and (2) The amelioration does not translate into epistemic loss"; due to its formulation in terms of non epistemic loss, such procedure eases off the pressure on the improvement requirement, while it restricts the various possible types of improvement to rationalist standards (cf. Sect. 2.2.1).

${ }^{18}$ On concepts, Cappelen (2018: 141) is quite unequivocal: "There's of course already a smorgasbord of options for how to think about concepts [...]. However, and this is the strange part, those who talk of conceptual engineering as operating on concepts don't start by making choices on this smorgasbord. They often just talk about 'concepts,' their engineering, and then leave it at that."
} 
(Sect. 3.2), respectively, that would be the most conducive to the research program of conceptual engineering as previously systematized (Sect. 2).

Remark 5 (Symmetric perspectives). One may distinguish between two opposed (and yet, complementary) perspectives on the research program of conceptual engineering: On one hand, top-down approaches, which require the theorization of what conceptual engineering is about (i.e. of its subject matter) prior to applying it, as a method, on specific study cases, and on the other hand, bottom-up approaches, according to which it is expected that "a theory of concepts [but what about 'engineering,' then?] will slowly emerge from a theory of conceptual engineering" (ConceptLab); taking up the bootstrapping challenge of re-engineering the concept of 'concept' and of '(cognitive) engineering' (Sect. 1) presupposes that one adopts the topdown perspective - as opposed to the minimalism of bottom-up approaches to conceptual engineering, which advise remaining neutral with regard to the main foundational issues of the research program (e.g. Burgess and Plunkett 2013a: 1095; Plunkett 2015: 846).

\subsection{Theory of concepts}

3.1.1 Research context Several inchoate understandings of concepts have been sketched out, albeit very roughly (note 18), within the field of conceptual engineering - leaving aside the eliminativism championed by the 'austerity framework' (Cappelen 2018: Sect. 4.3). ${ }^{19}$ One can classify these understandings according to a widely acknowledged distinction between philosophical and psychological approaches to concepts (Machery 2009: Sect. 2.2). Typically, philosophical approaches to concepts take them to be semantic entities endowed with 'semantic structure' (Machery 2010: 219), ${ }^{20}$ and focus on their semantic constituency in order to deliver a priori, analytic truth about the world (e.g. Jackson 1994, 1998; Peacocke 1992; Pitt 1999). By contrast, psychological approaches typically take concepts to be cognitive entities endowed with 'processing structures' (Machery 2010: 219), and focus on their operativeness in our higher cognitive competences in order to deliver empirical propositions about the mind (e.g. Murphy 2004). Somehow surprisingly in view of the characterization of the target domain of conceptual engineering (Sect. 2.1.2), most of the work that pertains, directly or not, to the research program of conceptual engineering and that teases out its underlying views on concepts endorses the philosophical/semantic approach to concepts. ${ }^{21}$ Whereas the defenders of the psychological/cognitive take on concepts remain a small minority - the only explicit one being Machery (2017: Chap. 7) (cf. also Plunkett 2015: 846; Prinzing 2017: 5, 14-5; Simion 2017: 10; Thomasson forthcoming). ${ }^{22}$ I suggest taking here a clear stand, against the current (viz. against standard theories of conceptual engineering).

3.1.2 A new direction My recommendation here is pretty straightforward: We should adopt a psychological approach to concepts for the purposes of conceptual engineering (cf. Sect. 3.1.1). This is indeed, I contend, the only way to fit in with the cognitive focus of conceptual engi-

\footnotetext{
${ }^{19}$ Pace Cappelen (2018: 104,157), such eliminativism does not correspond to that of Machery (2009: Chap. 8).

${ }^{20}$ NB. in what follows, Machery (2010: 206-31) may refer to comments by Couchman et al., Khemlani and Goodwin, Lalumera, Margolis and Laurence, Scarantino, Weiskopf, and Yermolayeva and Rakison.

${ }^{21}$ E.g. by taking concepts to be "linguistic entities" (Brun 2016: 1217), "contents of simple expressions" and "constituents of the contents of judgments" (Chalmers 2011: 549 [note 23]), "meanings of terms" (Plunkett 2015: 841), "constituent components or ingredients of thoughts" (Burgess and Plunkett 2013a: 1095; Plunkett 2016: 34), subject matter (Prinzing 2017: 4), and so on.

${ }^{22}$ NB. since Plunkett (2015) and Prinzing (2017) concurrently adopt the philosophical/semantic approach (see note 21), they may seem to promote some sort of "dual view" on concepts (cf. Sect. 3.1.2), perhaps similar to that defended by Margolis and Laurence (2007) (see also Machery 2010: 219-20), according to which concepts would be endowed with both semantic and processing structures.
} 
neering — viz. with its focus on concepts taken as cognitive devices (Sect. 2.1.2). ${ }^{23}$ With this in mind, I propose to build on a basic psychological characterization of concepts as the bodies of information about some referent (or class of referents) that are retrieved and used by default in the processes underlying the higher cognitive tasks that we perform about that referent (or class of referents) (Machery 2009: Chap. 1, 2015, 2017: Sect. 7.1) — whatever the ontological status of these or that referent(s) may be. And on that basis, I next propose to assume that the default bodies of information that concepts are divide into three different basic kinds (Machery 2009: Chap. 4), namely: Exemplars, whose structures are made of some particular exemplary instance(s) of a concept to which resemble the other members of the concept's extension (e.g. Medin and Schaffer 1978; Smith and Medin 1981); prototypes, whose structures consist of lists of typical properties that are statistically/probabilistically satisfied by the members of the concept's extension (e.g. Rosch 1973, 1975; Rosch and Mervis 1975); and theories, which are structured bodies of theoretical knowledge (viz. causal, functional, generic, and/or nomological explanatory principles) about the members of the concept's extension (e.g. Carey 1985, 2009; Gopnik and Meltzoff 1997). ${ }^{24}$ This assumption, along with its underlying basic psychological characterization of concepts (see above), sets out the background for developing a concept of 'concept' that I expect to be the most conducive for the research program of conceptual engineering (as systematized in Section 2).

3.1.3 The key concept At the background of this re-engineering project of the concept of 'concept' for the purposes of conceptual engineering is the assumption that concepts come under three different basic kinds (Sect. 3.1.2). A further step consists in drawing from a combination between some variants of hybrid theories of concepts (e.g. Gelman 2004; Keil 1989; Keil et al. 1998) and some variants of conceptual pluralism (e.g. Piccinini and Scott 2006; Weiskopf 2009 [as well as Machery 2009; Machery and Seppälä 2011]) in order to contend that the activation and use of the basic conceptual kinds are context-dependent and task-appropriate, respectively. On those grounds, my proposal is that, for the purposes of conceptual engineering, concepts should then be construed as multiply realizable functional kinds, that is: (i) As performing some specific causal/explanatory functions in our higher cognitive processes (e.g. abstraction, categorization, induction, etc.), and (ii) as realizable by several different basic kinds (viz. exemplars, prototypes, theories). ${ }^{25}$ Now, while it matches the conceptual ecumenism proclaimed, but never warranted, by some versions of conceptual engineering (e.g. Burgess and Plunkett 2013a: 1095; Plunkett 2015: 846), and arguably dismisses any ground for a sound "aversion to concepts" (Cappelen 2018: 157), this proposal for how to re-engineer the concept of 'concept' for the purposes of conceptual engineering is expected to theoretically secure and justify the maximum scope for the method of conceptual engineering on the world of our everyday life (cf. Rem. 3). Yet in the programmatic spirit of this paper, this proposal is a research hypothesis and, as such, it shall be further evaluated by comparison to alternative options, such as the 'heterogeneity hypothesis' of conceptual eliminativism (Machery 2009; Machery and Seppälä 2011), other versions of hybrid theories (e.g. Osherson and Smith 1981; Rips 1995; Rips et al. 1973; Smith et al. 1974), and the classical-philosophical views on concepts.

\footnotetext{
${ }^{23}$ For arguments against the semantic take on concepts for the purposes of conceptual engineering, see Greenough (Book manuscript) (as referred to in Greenough [forthcoming]).

${ }^{24}$ As is well known, these three theoretical entities correspond to three theoretical paradigms within the field of the psychology of concepts that have emerged in reaction to the rejection of the so-called 'classical theory' (or 'definitionism'), according to which concepts are definitional complexes that are composed of more basic semantic features, which, in turn, are meant to provide the necessary and sufficient conditions for an object to fall under them, together with their own identity conditions (see e.g. Margolis and Laurence 1999: Sect. 2; Murphy 2004: Chap. 2).

${ }^{25} \mathrm{NB}$. these different kinds can then be themselves sequentially ordered as an abstraction progress - that is, from exemplars to theories via prototypes (Machery 2010: 218, 224, 230) - in our multi-layered cognitive niches (Rem. 6).
} 
Remark 6 (A flexible method). To construe concepts as multiply realizable functional kinds implies their processing by the method of conceptual engineering to be implemented through different 'measures of appropriateness' (Sundell 2012: 757), depending on the kind of concept to be (re-)engineered, the cognitive function to be executed by this very concept, and the conceptual system it is meant to belong to (cf. Sect. 2.2.1), ${ }^{26}$ in other words: Depending on the operativeness of the concept to be (re-)engineered within the 'information modeling process' of our 'cognitive niche construction' (Floridi 2011: 291; Clark 2005, 2006); ${ }^{27}$ understanding such operativeness with a view to adapting the processing of a concept by the method of conceptual engineering requires in turn the ability to situate the concept under consideration in the multilayering of our cognitive niche (in terms of 'levels of abstraction' [Floridi 2008], so to say), which ultimately necessitates the development of a theory of cognition (viz. cognitive engineering) tailored for the purposes of conceptual engineering (Sect. 3.2).

\subsection{Theory of cognition}

3.2.1 Research context Very few things have been said on the concept of 'engineering,' in the case of (conceptual) cognition, and for the purposes of conceptual engineering, except that it somehow involves an intentional and explicit design (e.g. Brun 2017: 2, 26 [see also Brun 2016: 1233 note 41]). In line with Prinzing (2017: 17) and Thomasson (forthcoming), this paper disagrees here in maintaining that 'engineering' simply designates the process through which concepts are designed as artificial (viz. socio-cultural and historical) products endowed with specific cognitive function. As for the concept of 'cognition,' which underlies the conception of concepts as cognitive devices (Sect. 2.1.2), the only hints that have been made explicitly, with respect to the functionalist take on concepts that characterizes conceptual engineering (Sect. 2.2.1), call for a broader perspective on our conceptual apparatuses. ${ }^{28}$ The remainder of this section goes a bit further and tries to account for "how a theory of conceptual engineering [does] fit into an overall theory of mind" and cognition (Cappelen 2017: 14). For this purpose, I start with a widely acknowledged opposition between, on one hand, computational approaches to cognition, which take it to be an information-processing operation internally performed by an individual mind/brain isolated from its environment (e.g. Garson 2016; Milkowski 2018; Rescorla 2017; Waskan 2018), and on the other hand, embodied-embedded approaches, which take cognition to be an information-construction operation resulting from the coordinated interaction of the mind/brain, the body, and the environment (e.g. Cowart 2018; Neuwen et al. forthcoming; Wilson and Foglia 2017). And against this background, I suggest taking a clear stand — again, against the current (viz. against mainstream analytic philosophy).

3.2.2 A new direction My recommendation is here again pretty straightforward: We should adopt an embodied-embedded approach to cognition for the purposes of conceptual engineering

\footnotetext{
${ }^{26}$ To put it straight: In my view, one should not re-engineer, e.g., the concept of 'fish' in the kitchen (where counting whales as fishes may facilitate the execution of the cognitive task at stake) as in the biology classroom (where the very same inclusion would impede the cognitive task at stake), as one is dealing here with different kinds of concepts - for other compelling examples borrowed from Moby Dick or about the lay vs. scientific concepts of 'berries,' see Chalmers (2011: 519) and Brun (2016: 1219), respectively; note that this obviously goes against the rationalist/scientistic trend in the conceptual engineering movement according to which there is always only one standard to assess and one way to improve our (otherwise deficient) concepts (Sect. 2.2.1).

${ }^{27}$ Drawing from evolutionary biology (Odling-Smee et al. 2003; Sterelny 2003), the concept of 'cognitive niche construction' was originally introduced and defined by Clark (2005: 256) as "the process by which animals build physical structures that transform problem spaces in ways that aid (or sometimes impede) thinking and reasoning about some target domain or domains" (see also Clark 2006) - more on this below (Sect. 3.2.3).

${ }^{28}$ As Thomasson (forthcoming) puts it: "I think it is an under-appreciated point that conceptual engineering, no less than civil, does not take place in a vacuum, and that it is extremely important to note and be responsive to the inferential connections between the term in question (whether one we are considering revising or eliminating) and our other terms and broader practices."
} 
(cf. Sect. 3.2.1). This is indeed, I contend, the only way to fit in with the 'poietic' dimension of conceptual engineering (Sect. 2.1.1) - viz. with its creative-productive take on concepts as cognitive artifactual devices open to re-engineering projects (Sect. 2.1.3). ${ }^{29} \mathrm{With}$ this in mind, I propose to build on a basic 'embodied-embedded conception of concepts' as entities that emerge in larger socio-cultural and historical contexts (Dutilh Novaes 2016: 87, 92-3, 104 [notes 30, 36]; see also Plunkett 2016: 54-5). On that basis, I next propose to assume a combined characterization of 'cognition' by two complementary frameworks, namely: On one hand, 'cognitive integration,' according to which cognition lies in the socio-culturally shaped embodied interactions of the organism with the informational structure of its environment (Menary 2007), ${ }^{30}$ and on the other hand, 'constructionism' in philosophy of information, according to which cognition is about the temporal, multi-agent creation of informational structures that enable the communication of the cognitive agent with its environment (Floridi 2011: 282-4, 290-1). ${ }^{31}$ This combination of integrationism and constructionism, along with its underlying basic embodiedembedded characterization of concepts (see above), sets out the background for developing a concept of '(cognitive) engineering' that I expect to be the most conducive for the research program of conceptual engineering (as systematized in Section 2).

3.2.3 The key concept At the background of this engineering project of the concept of '( $\operatorname{cog}$ nitive) engineering' for the purposes of conceptual engineering is the assumption that cognition is an engineering process - namely, that of the informational relationship we enact, as cognitive agents, with out environment (Sect. 3.1.2). A further step consists in drawing on the work in 'cognitive niche construction' theory in order to construe the engineering of that informational relationship as the process of making salient and structuring the epistemic resources of our environmental niches - or in other words, of constructing our cognitive niches - so as to better interact with some target domain (e.g. better perform some given cognitive task) (cf. note 27). And on those grounds, my proposal is that, for the purposes of conceptual engineering, (cognitive) engineering should then be construed as the information modeling process of our cognitive niche construction, that is: (i) As the process of creating informational artifacts (a.k.a. 'concepts' as default bodies of information), and (ii) as the operation of using these artifacts as cognitive devices to shape and edit our (understanding of our) environment so as to make it intelligible (cf. Floridi 2011: 285, 291, 301; Menary 2007: Part II). ${ }^{32}$ Now, while it matches the non-conceptual transformational power proclaimed, but never really warranted, by some versions of conceptual engineering (Burgess and Plunkett 2013a: 1091-2, 1096-7; Scharp forthcoming), ${ }^{33}$ and dispels the common concerns about the compatibility of conceptual engineering with externalism (namely, by endorsing a strong variant of active externalism), without any recourse to some kind of "Inscrutable-Lack of Control-Will Keep trying" principle (note 4), this proposal for how to engineer the concept of '(cognitive) engineering' for the purposes of conceptual engineering is expected to theoretically secure and justify the maximum impact for the method of conceptual engineering on our worldview (cf. Rem 6). Yet in the programmatic spirit of this paper, this proposal is another research hypothesis, and it shall be, as such, further evaluated by compari-

\footnotetext{
${ }^{29}$ For arguments against basic internalism, see Cappelen (2018: Sect. 7.1.1).

${ }^{30}$ See also Menary $(2010,2012,2013,2015)$.

${ }^{31}$ Note that constructionism is here obviously in plain contrast to any kind of 'wysiwyg' theory of cognition (e.g. Eklund 2015: 377-8), according to which our higher cognition (e.g. knowledge) consists in a passive, receptive, and mimetic re-production of semantic information ("the message from the world"), which may thus be taken to be a-temporal and single-agent (Floridi 2011: 282-4, 291, 301).

${ }^{32}$ Cf. also Sterelny's concept of 'epistemic engineering' defined as "organizing our physical environment in ways that enhance our information-processing capacities" (Sterelny 2012: xii [see also Menary 2014, 2015]).

${ }^{33}$ As they say: "The first point here is that our conceptual repertoire determines not only what we can think and say but also, as a result, what we can do and who we can be. In other words, which concepts we use has an important impact on the space of possible actions and lives available to us" (Burgess and Plunkett 2013a: 1091-2); and "Through conceptual engineering, we can take some control over what we can think, say, do, and be" (Scharp forthcoming).
} 
son to alternative options, such as those relying on the conceptions of cognition that have been developed within the framework of computational theories of mind (classical or connectionist), as well as within that of anti-4E cognitive science (e.g. Adams and Aizawa 2008).

\section{Conclusion}

This paper is a programmatic paper and its purpose was to provide some guidelines for developing the theoretical (viz. conceptual) foundations of conceptual engineering construed as a (forthcoming) method for the cognitive optimization of our conceptual apparatuses - viz. of our conceptual repertoires and schemes working as cognitive devices. Aiming at making conceptual engineering an actionable method that is relevant and useful across a wide range of different areas, its underlying working hypothesis was that to implement conceptual engineering as such transferable method requires the prior understanding of the subject matter of conceptual engineering through adequate theories of concepts and cognition. To this end, after having presented in a systematic way the research program of conceptual engineering with a focus on its foundational issues (Sect. 2), I have elaborated proposals for developing the concept of 'concept' as multiply realizable functional kinds (Sect. 3) and the concept of '(cognitive) engineering' as the information modeling process of our cognitive niche construction (ibid.) - in both cases, for the purposes of the research program of conceptual engineering (as systematized in Section 2). And on that basis, my overall final proposal is that conceptual engineering is about engineering concepts inasmuch as conceptual engineering deals with (re-)modeling the multiply realizable default bodies of information that structure (as different kinds, on different levels) our cognitive relationships with reality at large. And by laying the theoretical foundations of conceptual engineering in this way, I claim to have in principle theoretically secured and justified the maximum scope and impact for the method of conceptual engineering on the world of our everyday life and on our worldview, respectively - while doing so may indeed be expected in order to ground the systematic unified framework that will specify why, when, and how to use conceptual engineering.

\section{References}

Adams, Frederick and Kenneth Aizawa (2008). The Bounds of Cognition. Oxford: Blackwell.

Blackburn, Simon (1999). Think: A Compelling Introduction to Philosophy. Oxford: Oxford University Press.

Brandom, Robert (2001). "Modality, normativity, and intentionality". Philosophy and Phenomenological Research 63.3, 587-609.

Brun, Georg (2016). "Explication as a method of conceptual re-engineering". Erkenntnis 81.6, $1211-1241$.

- (2017). "Conceptual re-engineering: from explication to reflective equilibrium". Synthese, 1-30. DOI: $10.1007 / \mathrm{s} 11229-017-1596-4$.

Burgess, Alexis (forthcoming). "Never say 'never'”. In: Conceptual Engineering and Conceptual Ethics. Ed. by Alexis Burgess, Herman Cappelen, and David Plunkett. Oxford: Oxford University Press.

Burgess, Alexis and David Plunkett (2013a). "Conceptual ethics I". Philosophy Compass 8.12, 1091-1101.

- (2013b). "Conceptual ethics II". Philosophy Compass 8.12, 1102-1110.

Cappelen, Herman (2017). "Why philosophers shouldn't do semantics". Review of Philosophy and Psychology. DoI: 10.1007/s13164-017-0340-9. 
Cappelen, Herman (2018). Fixing Language: Conceptual Engineering and the Limits of Revision. Oxford: Oxford University Press.

- (forthcoming). "Conceptual engineering: The Master Argument". In: Conceptual Engineering and Conceptual Ethics. Ed. by Alexis Burgess, Herman Cappelen, and David Plunkett. Oxford: Oxford University Press.

Cappelen, Herman and David Plunkett (forthcoming). "A guided tour of conceptual engineering and conceptual ethics". In: Conceptual Engineering and Conceptual Ethics. Ed. by Alexis Burgess, Herman Cappelen, and David Plunkett. Oxford: Oxford University Press.

Cappelen, Herman, Øystein Linnebo, and Camilla Serck-Hanssen, eds. ConceptLab. Website. Department of Philosophy - Faculty of Humanities - University of Oslo. URL: https : // conceptualengineering.info.

Carey, Susan (1985). Conceptual Change in Childhood. Cambridge (MA): MIT Press.

- (2009). The Origin of Concepts. Oxford: Oxford University Press.

Carnap, Rudolf (1950). Logical Foundations of Probability. Chicago: University of Chicago Press.

- (1963). "Replies and systematic expositions". In: The Philosophy of Rudolf Carnap. Ed. by Paul Arthur Schilpp. La Salle: Open Court, 859-1113.

Chalmers, David John (2011). "Verbal Disputes". Philosophical Review 120.4, 515-566.

Clark, Andy (2005). "Word, niche and super-niche: how language makes minds matter more". THEORIA. Revista de Teoría, Historia y Fundamentos de la Ciencia 20.3, 255-268.

- (2006). "Language, embodiment, and the cognitive niche". Trends in Cognitive Sciences 10.8, $370-374$.

Cowart, Monica (2018). "Embodied cognition". In: The Internet Encyclopedia of Philosophy. urL: https://www. iep.utm. edu/embodcog/.

Dutilh Novaes, Catarina (2016). "Conceptual genealogy for analytic philosophy". In: Beyond the Analytic-Continental Divide: Pluralist Philosophy in the Twenty-First Century. Ed. by Jeffrey A. Bell, Andrew Cutrofello, and Paul M. Livingston. New York: Routledge, 74-108.

- (2018). "Carnapian explication and ameliorative analysis: A systematic comparison". Synthese, 1-24. DOI: 10.1007/s11229-018-1732-9.

Dutilh Novaes, Catarina and Erich Reck (2017). "Carnapian explication, formalisms as cognitive tools, and the paradox of adequate formalization". Synthese 194.1, 195-215.

Eklund, Matti (2014). "Replacing Truth?" In: Metasemantics: New Essays on the Foundations of Meaning. Ed. by Alexis Burgess and Brett Sherman. Oxford: Oxford University Press, 293-310.

- (2015). "Intuitions, conceptual engineering, and conceptual fixed points". In: The Palgrave Handbook of Philosophical Methods. Ed. by Chris Daly. Dordrecht: Springer, 363-385.

Floridi, Luciano (2008). "The method of levels of abstraction". Minds and Machines 18.3, 303329.

- (2011). "A defence of constructionism: Philosophy as conceptual engineering". Metaphilosophy 42.3, 282-304.

Garson, James (2016). "Connectionism". In: The Stanford Encyclopedia of Philosophy. Ed. by Edward N. Zalta. Metaphysics Research Lab - Stanford University. URL: https ://plato . stanford.edu/archives/win2016/entries/connectionism/.

Gelman, Rochel (2004). "Cognitive development". In: Stevens' Handbook of Experimental Psychology. Memory and Cognitive Processes. Ed. by Hal Pashler and Douglas L. Medin. Vol. 2. New York: Wiley.

Gopnik, Alison and Andrew N. Meltzoff (1997). Words, Thoughts, and Theories. Cambridge (MA): MIT Press.

Greenough, Patrick (Book manuscript). Against Conceptual Engineering. 
Greenough, Patrick (forthcoming). "Neutralism and conceptual engineering". In: Conceptual Engineering and Conceptual Ethics. Ed. by Alexis Burgess, Herman Cappelen, and David Plunkett. Oxford: Oxford University Press.

Jackson, Frank (1994). "Armchair metaphysics". In: Philosophy in mind: The Place of Philosophy in the Study of Mind. Ed. by Michael Michaelis and John O'Leary-Hawthorne. Dordrecht: Kluwer, 23-42.

- (1998). From Metaphysics to Ethics: A Defence of Conceptual Analysis. Oxford: Oxford University Press.

Keil, Frank C. (1989). Concepts, Kinds, and Cognitive Development. Cambridge (MA): MIT Press.

Keil, Frank C. et al. (1998). "Two dogmas of conceptual empiricism: Implications for hybrid models of the structure of knowledge". Cognition 65.2, 103-135.

Löwe, Benedikt and Thomas Müller (2011). "Data and phenomena in conceptual modelling". Synthese 182.1, 131-148.

Machery, Edouard (2009). Doing without Concepts. Oxford: Oxford University Press.

- (2010). "Précis of Doing Without Concepts". With open peer commentary and author's response. Brain and Behavioral Science 33.2, 195-244.

- (2015). "By default". In: The Conceptual Mind: New Directions in the Study of Concepts. Ed. by Stephen Laurence and Eric Margolis. Cambridge (MA): MIT Press, 567-588.

- (2017). Philosophy within its Proper Bounds. Oxford: Oxford University Press.

Machery, Edouard and Selja Seppälä (2011). "Against hybrid theories of concepts". Anthropology and Philosophy 10, 99-126.

Margolis, Eric and Stephen Laurence (1999). "Concepts and cognitive science". In: Concepts: Core Readings. Ed. by Stephen Laurence and Eric Margolis. Cambridge (MA): MIT Press, $3-81$.

- (2007). "The ontology of concepts-abstract objects or mental representations?" Nô̂s 41.4, 561-593.

Marques, Teresa (2017). "What metalinguistic negotiations can't do". Phenomenology and Mind $12,40-48$.

Medin, Douglas L. and Margueritte M. Schaffer (1978). "Context theory of classification learning". Psychological Review 85, 207-238.

Menary, Richard (2007). Cognitive Integration: Mind and Cognition Unbounded. New York: Palgrave Macmillan.

- ed. (2010). Phenomenology and the Cognitive Sciences 9.4: Special Issue: 4E Cognition: Embodied, Embedded, Enacted, Extended.

- (2012). "Cognitive practices and cognitive character". Philosophical Explorations 15.2, 147164.

- (2013). "Cognitive integration, enculturated cognition and the socially extended mind". Cognitive Systems Research 25, 26-34.

- (2014). "Neural plasticity, neuronal recycling and niche construction". Mind \& Language 29.3, 286-303.

- (2015). "Mathematical cognition: A case of enculturation". In: Open MIND. Ed. by Thomas K. Metzinger and Jennifer M. Windt. Frankfurt: MIND Group. Chap. 25(T).

Milkowski, Marcin (2018). "The computational theory of mind". In: The Internet Encyclopedia of Philosophy. URL: http://www.iep.utm.edu/compmind/.

Murphy, Gregory (2004). The Big Book of Concepts. Cambridge (MA): MIT Press.

Neuwen, Albert, Leon de Bruin, and Shaun Gallagher (forthcoming). The Oxford Handbook of $4 E$ Cognition. Oxford: Oxford University Press.

Odling-Smee, F. John, Kevin N. Laland, and Marcus W. Feldman (2003). Niche Construction: The Neglected Process in Evolution. Princeton: Princeton University Press. 
Osherson, Daniel N. and Edward E. Smith (1981). "On the adequacy of prototype theory as a theory of concepts". Cognition 9.1, 35-58.

Peacocke, Christopher (1992). A Study of Concepts. Cambridge (MA): MIT Press.

Piccinini, Gualtiero and Sam Scott (2006). "Splitting concepts". Philosophy of Science 73.4, 390409.

Pitt, David (1999). "In defense of definitions". Philosophical Psychology 12.2, 139-156.

Plunkett, David (2015). "Which concepts should we use? Metalinguistic negotiations and the methodology of philosophy". Inquiry 58.7-8, 828-874.

- (2016). "Conceptual history, conceptual ethics, and the aims of inquiry: A framework for thinking about the relevance of the history/genealogy of concepts to normative inquiry". Ergo 3.2, 27-62.

Prinzing, Michael (2017). "The revisionist's rubric: Conceptual engineering and the discontinuity objection". Inquiry, 1-27. Dor: 10.1080/0020174X.2017.1385522.

Quine, Willard Van Orman and Rudolf Carnap (1991). Dear Carnap, Dear Van: The Quine-Carnap Correspondence and Related Work. Ed. by Richard Creath. Berkley: University of California Press.

Rescorla, Michael (2017). "The Computational Theory of Mind". In: The Stanford Encyclopedia of Philosophy. Ed. by Edward N. Zalta. Metaphysics Research Lab - Stanford University. URL: https://plato.stanford.edu/archives/spr2017/entries/computational-mind/.

Rips, Lance J. (1995). "The current status of research on concept combination". Mind E Language $10.1-2,72-104$.

Rips, Lance J., Edward J. Shoben, and Edward E. Smith (1973). "Semantic distance and the verification of semantic relations". Journal of Verbal Learning and Verbal Behavior 12.1, 1-20.

Rosch, Eleanor (1973). "Natural categories". Cognitive Psychology 4.3, 328-350.

- (1975). "Cognitive representations of semantic categories". Journal of Experimental Psychology: General 104.3, 192-233.

Rosch, Eleanor and Carolyn B. Mervis (1975). "Family resemblance: Studies in the internal structure of categories". Cognitive Psychology 7.4, 573-605.

Scharp, Kevin (2013). Replacing Truth. Oxford: Oxford University Press.

- (forthcoming). "Philosophy as the study of inconsistent concepts". In: Conceptual Engineering and Conceptual Ethics. Ed. by Alexis Burgess, Herman Cappelen, and David Plunkett. Oxford: Oxford University Press.

Scharp, Kevin and Stewart Shapiro (2017). "Revising inconsistent concepts". In: Reflections on the Liar. Ed. by Bradley Armour-Garb. Oxford: Oxford University Press, 257-280.

Simion, Mona (2017). "The 'should' in conceptual engineering". Inquiry, 1-15. Dor: 10.1080/ $0020174 X .2017 .1392894$.

Smith, Edward E. and Douglas L. Medin (1981). Categories and Concepts. Cambridge: Harvard University Press.

Smith, Edward E., Edward J. Shoben, and Lance J. Rips (1974). "Structure and process in semantic memory: A featural model for semantic decisions." Psychological Review 81.3, 214241.

Sterelny, Kim (2003). Thought in a hostile world: The evolution of human cognition. Oxford: Blackwell.

- (2012). The Evolved Apprentice: How Evolution Made Humans Unique. Cambridge (MA): MIT press.

Sundell, Timothy (2012). "Disagreement, error, and an alternative to reference magnetism". Australasian Journal of Philosophy 90.4, 743-759.

Tanswell, Fenner Stanley (2017). "Conceptual engineering for mathematical concepts". Inquiry, 1-33. DOI: $10.1080 / 0020174 \mathrm{X} .2017 .1385526$. 
Thomasson, Amie L. (forthcoming). "A pragmatic method for conceptual ethics". In: Conceptual Engineering and Conceptual Ethics. Ed. by Alexis Burgess, Herman Cappelen, and David Plunkett. Oxford: Oxford University Press.

Waskan, Jonathan (2018). "Connectionism". In: The Internet Encyclopedia of Philosophy. URL: http://www. iep.utm.edu/connect/.

Weiskopf, Daniel Aaron (2009). "The Plurality of Concepts". Synthese 169.1, 145-173.

Wilson, Robert A. and Lucia Foglia (2017). "Embodied Cognition". In: The Stanford Encyclopedia of Philosophy. Ed. by Edward N. Zalta. Metaphysics Research Lab - Stanford University. URL: https://plato.stanford.edu/archives/spr2017/entries/embodied-cognition/. 